\title{
Alguns aspectos do uso do hipoclorito de sódio em Endodontia
}

\author{
Nicolau F. Milano* \\ Vera Girardi** \\ Ana Maria Bergold*** \\ Lea Gusmão Chiapini****
}

\begin{abstract}
RESUMO
Os autores estudaram soluçōes de $\mathrm{NaOCl}$ de uso endodôntico, em diferentes concentraçōes de cloro, buscando esclarecer os seguintes tópicos:
\end{abstract}

a) Velocidade de "envelhecimento" (perda do teor de cloro) nas diferentes concentraçōes - 5\%, 2,5\% - 1\% - 0,5\%

b) Tempo de dissoluçăo de uma polpa dentária (in vitro) das diferentes concentraçōes.

c) Procura de um estabilizador para o $\mathrm{NaOCl}$.

\begin{abstract}
SUMMARY
This paper studied the $\mathrm{NaOCl}$ solution in endodontic use, acording diferent concentrations some properties was studied:

a) The lost of $\mathrm{Cl}$ in diferent concentrations $(5 \%-2,5 \%-1 \%-0,5 \%)$

b) Measure the time of proteolitic efect over dental pulp in diferent concentrations

c) Find way to stabilized the $\mathrm{NaOCl}$ solution
\end{abstract}

\section{DESCRITORES}

ENDODONTIA • AUXILIARES QUÍMICOS EM ENDODONTIA • TRATAMENTO DE CANAIS • FARMACOLOGIA

\section{INTRODUÇÃO}

Apesar de ser citado na literatura desde 1792 , o Hipoclorito de sódio - $\mathrm{NaOCl}$ - foi introduzido na endodontia em 1942 por Grossman e Meimann. Desde então vem sendo usado na irrigação de canais radiculares, especialmente nos infectados.

Sua importância é devida a certas propriedades que apresenta como, poder germicida, dissolvente de tecido pulpar, ação anti-tóxica, ação branqueadora dos dentes, desodorizante e é pouco irritante aos tecidos vivos, quando em baixas concentraçōes de cloro.

As soluçōes usadas em endodontia variam de $0,5 \%$ a $5 \%$. Os preparados comerciais encontrados no comércio são, o líquido de Dakin $(0,5 \%)$, a solução Miltom (1\%) e a soda clorada $(5 \%)$.

As soluçōes de $\mathrm{NaOCl}$ são inestáveis. Elas perdem, de forma considerável, sua efetividade com o passar do tempo, com excessão da solução Miltom a qual possui um estabilizador.

Este fato é muito importante na medida em que as soluçōes permanecem estocadas no comércio. Assim sendo, em verdade, quase nunca se sabe a concentração de $\mathrm{Cl}$ do $\mathrm{NaOCl}$ que está sendo usado, fato indesejável para um bom desempenho da endodontia.

Uma tentativa de controlar esse problema é o objetivo do presente trabalho.

\section{PROPOSIÇÃO}

1. Estabelecer uma cronologia do enveIhecimento dos $\mathrm{NaOCl}$ que permita ter-se uma idéia da perda de concentraçāo de $\mathrm{Cl}$ ao longo do tempo.

2. Determinar o tempo médio em que uma polpa é dissolvida "in vitro" sob a ação do $\mathrm{NaOCl}$ em diferentes concen- traçōes.

3. Pesquisar um estabilizador para os $\mathrm{NaOCl}$.

\section{REVISÃO BIBLIOGRÁFICA}

Raros foram os autores que pesquisaram 0 uso endodôntico dos $\mathrm{NaOCl}$. A maioria cita trabalhos de Grossman, Grossman e Meimann, os quais, sem dúvida, foram os autores que mais se dedicaram ao tema.

Todas as obras consultadas são unânimes quanto à grande instabilidade dos $\mathrm{NaOCl}$. Ela decorre da liberação de cloro,

\footnotetext{
* Prof. Titular de Endodontia da F.O./UFRGS ** C.D. Cirurgiā Dentista

*** Profa. Adjunta de Química Farmacêutica da F.F./UFRGS

**** Profa. Assistente de Química Farmacêutica da F.F./UFRGS
} 
fato que, aliás, contribui para a limpeza e desinfecçảo do canal.

$\mathrm{Da}$ instabilidade decorre a impossibilidade de se estocar o produto. Segundo Bazerque (2), Berbert e cols. (3), Leonardo e cols. (18), Grossman (11) e Maisto (19), o tempo de estocagem máximo seria de 3 meses, devendo ser guardado em vidro de cor âmbar ao abrigo da luz e calor. Filgueiras e Mello (10) recomendam preparar-se soluçōes frescas a cada 2 meses mais ou menos. Soler e Schocron (28) sugerem a renovaçāo a cada mês. Quanto ao líquido de Dakin especificamente, Coolidge (7) e Sales Cunha (26) afirmam que poderia ser guardado apenas por uma semana sem decomposiçāo.

Das soluçōes de $\mathrm{NaOCl}$ encontráveis no mercado, a única estável é a solução de Miltom, descrita por De Deus (8) como sendo uma solução estável de $\mathrm{NaOCl}$ com $1 \%$ de cloro ativo e cloreto de sódio a $16,5 \%$ com pH tamponado.

ADA (1) e Bazerque (2) afirmam que um meio fortemente alcalino estabiliza o hipoclorito. Redish (24) comenta que a alcalinidade aumenta a estabilidade mas diminui o poder germicida e aumenta a irritabilidade da soluçāo.

Há concordância quanto à capacidade de dissolver a polpa e tecidos necróticos encontrados no interior do canal. Grossman $(10,11)$ citado também por Leonardo e cols. (18), Paiva e Alvares (21) e Soler e Schocron (28) afirmam que uma polpa pode ser totalmente dissolvida pela soda clorada em tempo que varia de 20 minutos a 02 horas.

Autores como Berbert e cols. (3), Hizatugo e Valdrighi (13), Holland (14) e Leonardo e cols. (18) afirmam que 0 poder dissolvente é diretamente proporcional à concentraçāo da soluçăo de $\mathrm{NaOCl}$. Assim sendo, a soda clorada dissolveria uma polpa mais rapidamente do que o líquido de Dakin.

Leonardo e cols. (18) e Pucci (23) citam observaçōes de Klein comprovando que a histólise, pela açāo do cloro sobre os tecidos necrosados produz-se muito mais rapidamente quando os tecidos afetados năo foram submetidos à açāo de outros medicamentos. Isto significa que uma polpa $\theta$ dissolvida com maior rapidez se submetida à açāo do $\mathrm{NaOCl}$, sem o uso anterior de outros medicamentos tais como fenol, creosoto, tri cresol formalina, etc..

\section{MATERIAL E MÉTODO DE TRABALHO}

\section{Envelhecimento do $\mathrm{NaOCl}$}

Houve, de início, extrema dificuldade em se conseguir amostras de $\mathrm{NaOCl}$ em diferentes concentraçōes dada à enorme disparidade entre as concentraçōes anunciadas e as verdadeiramente existentes.

Vencidos esses obstáculos, foi finalmente obtido material para o estudo proposto.

As soluçōes utilizadas foram:

a. Líquido de Dakin a 0,4\% (Lab. Catarinense).

b. Soluçāo de Miltom a $1 \%$ (em pleno período de validade).

c. Soluçāo Milton a 1\% (ao final do período de validade).

d. Solução de Labarraque a 2,5\%.

e. Soda clorada a $5 \%$.

Estas soluçōes foram tituladas a cada 30 dias para verificaçāo da percentagem de cloro ativo na soluçāo.

No caso da soluçāo Miltom, utilizamos dois frascos contendo a solução, com prazos de validade diferentes, com o objetivo de verificar-se a estabilidade efetiva.

\section{Tempo de dissoluçáo de polpa}

Para a verificação "in vitro" do tempo de dissolução de uma polpa, utilizaram-se as mesmas soluçōes citadas anteriormente.

Logo após ter sido feita uma pulpectomia, a polpa foi colocada em vidro transparente contendo uma das soluçōes em estudo, passando a ser observada até a dissolução completa da polpa. Anotou-se o tempo levado desde o primeiro contato da polpa com o $\mathrm{NaOCl}$ até a total dissoluçã̃o da mesma.

Tomou-se o cuidado para que a polpa năo entrasse em contato com nenhuma outra solução que nảo fosse o $\mathrm{NaOCl}$.

\section{Estabilização}

$\mathrm{Na}$ busca da estabilização utilizaram-se substâncias potencialmente estabilizadoras do $\mathrm{NaOCl}$ ao qual foram adicionadas.

Tituladas tais soluçōes, foram comparados os resultados aos das soluçōes que não continham nenhuma outra substância (item 1).
A escolha das subståncias experimentadas baseou-se nas informaçōes da literatura e em comunicaçōes pessoais.

$\mathrm{Na}$ primeira tentativa usou-se uma soluçāo com concentraçăo em torno de 5\%. À metade do volume acrescentou-se $16,5 \%$ de $\mathrm{NaCl}$, e à outra metade foi mantida como controle. A estabilizaçāo neste caso, baseia-se no ion comum. $\mathrm{O} \mathrm{NaCl}$ foi a primeira substância testada, por ser componente da soluçảo Miltom, a qual é estável.

Além disso tentou-se tamponar a solução após verificarmos que o produto comercial estabilizado (sol. Miltom) tinha o pH em torno de 10.

Procurou-se obter o mesmo preparando-se um tampão pH 10 (USP XXI pag. 1420). Para isso utilizaram-se $50 \mathrm{ml}$ de ácido bórico e cloreto de potássio 0,2M e $43,7 \mathrm{ml}$ de hidróxido de sódio 0,2M. Completando o volume para $200 \mathrm{ml}$ obtém-se um $\mathrm{pH} 10$.

Afim de trabalhar-se com menor número possivel de constituintes estranhos, procurou-se substituir a soluçăo de cloreto de potássio $0,2 \mathrm{M}$ por soluçāo de cloreto de sódio $0,2 \mathrm{M}$, mantendo os demais componentes.

Estas soluçōes foram acrescentadas a um volume conhecido de soluçāo de $\mathrm{NaOCl}$ com aproximadamente 2,5\% de cloro ativo até obtenção de pH 10.

\section{RESULTADOS}

Os resultados serāo apresentados em função dos grupos do trabalho:

a. Envelhecimento do $\mathrm{NaOCl}$.

b. Tempo para dissoluçảo de uma polpa.

c. Estabilidade dos $\mathrm{NaOCl}$.

\section{a. Envelhecimento dos $\mathrm{NaOCI}$}

Com as titulaçōes, obtivemos uma relaçăo cronológica da perda de cloro, conforme mostram a seguir a tabela e o gráfico.

\begin{tabular}{|c|c|c|c|c|c|c|}
\hline Solução & $\begin{array}{c}\text { LlQ. DAKIN } \\
(\mathbf{0 , 4} \%)\end{array}$ & $\begin{array}{c}\text { SOL. MILTON } \\
(\mathbf{1} \%)\end{array}$ & $\begin{array}{c}\text { SOL. LABARRA- } \\
\text { QUE }(2,5 \%)\end{array}$ & $\begin{array}{c}\text { SODA CLORADA } \\
\text { (NODON }(5 \%)\end{array}$ & $\begin{array}{c}\text { SODA CLORADA } \\
\text { HOMEODERM }(5 \% 9\end{array}$ & $\begin{array}{c}\text { SODA CLORADA } \\
\text { HCPA (5,25\%) }\end{array}$ \\
\hline $1:$ & $0,21 \%$ & $1,071 \%$ & $2,26 \%$ & $2,96 \%$ & $4,09 \%$ & $5,14 \%$ \\
$2:$ & $0,22 \%$ & $1,07 \%$ & $2,2 \%$ & $2,94 \%$ & $3,97 \%$ & $4,64 \%$ \\
$3:$ & $0,199 \%$ & - & $2,261 \%$ & $2,86 \%$ & $3,905 \%$ & $4,26 \%$ \\
$4:$ & $0,209 \%$ & - & $2,22 \%$ & $2,838 \%$ & $3,54 \%$ & $4,013 \%$ \\
$5:$ & $0,212 \%$ & - & $2,26 \%$ & $2,663 \%$ & $3,386 \%$ & $3,80 \%$ \\
$6:$ & $0,21 \%$ & $1,075 \%$ & $2,259 \%$ & $2,645 \%$ & $2,985 \%$ & $3,822 \%$ \\
$7:$ & $0,213 \%$ & $1,024 \%$ & $2,213 \%$ & $2,624 \%$ & $2,794 \%$ & $3,18 \%$ \\
$8:$ & - & - & $2,186 \%$ & $2,663 \%$ & $2,51 \%$ & $2,971 \%$ \\
$9:$ & - & $0,987 \%$ & $2,159 \%$ & $2,593 \%$ & $2,266 \%$ & $2,698 \%$ \\
$10:$ & - & - & $2,169 \%$ & - & $2,07 \%$ & $1,918 \%$ \\
$11:$ & - & $0,982 \%$ & $2,182 \%$ & - & $1,876 \%$ & $1,716 \%$ \\
$12:$ & - & $0,978 \%$ & $2,143 \%$ & - & $1,741 \%$ & $1,383 \%$ \\
\hline
\end{tabular}

TABELA 1: Perda de cloro ativo nas diversas soluçōes de Hipoclorito de Sódio (titulaçōes mensais)

R. Fac. Odontol.

Porto Alegre
V. 32

N. 1

p.8-10

JULHO

1991 


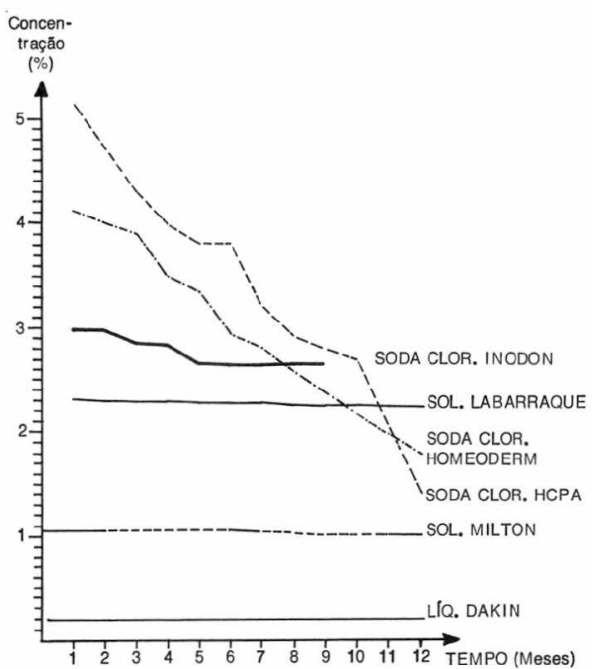

GRÁFICO 1: Perda de cloro ativo nas diversas soluçōes de Hipoclorito de Sódio.

\section{b. Tempo para dissoluçáo de uma polpa}

Os tempos de dissoluçāo da polpa obtidos foram os seguintes:

\begin{tabular}{|c|c|c|c|c|}
\cline { 1 - 4 } Amostra & $0,5 \%$ & $1 \%$ & $2,5 \%$ & $5 \%$ \\
\cline { 1 - 4 } 1 & $1 \mathrm{~h} 48 \mathrm{~min}$ & $2 \mathrm{~h} 05 \mathrm{~min}$ & $1 \mathrm{~h} 20 \mathrm{~min}$ & $32 \mathrm{~min}$ \\
2 & $2 \mathrm{~h} 09 \mathrm{~min}$ & $2 \mathrm{~h} 45 \mathrm{~min}$ & $1 \mathrm{~h} 35 \mathrm{~min}$ & $52 \mathrm{~min}$ \\
3 & $3 \mathrm{~h} 40 \mathrm{~min}$ & $2 \mathrm{~h} 50 \mathrm{~min}$ & $1 \mathrm{~h} 01 \mathrm{~min}$ & $55 \mathrm{~min}$ \\
4 & $2 \mathrm{~h} 30 \mathrm{~min}$ & $2 \mathrm{~h} 30 \mathrm{~min}$ & $2 \mathrm{~h} 50 \mathrm{~min}$ & $1 \mathrm{~h} 44 \mathrm{~min}$ \\
5 & $2 \mathrm{~h} 25 \mathrm{~min}$ & $2 \mathrm{~h} 00 \mathrm{~min}$ & $1 \mathrm{~h} 12 \mathrm{~min}$ & $1 \mathrm{~h} 10 \mathrm{~min}$ \\
6 & $2 \mathrm{~h} 45 \mathrm{~min}$ & $2 \mathrm{~h} 10 \mathrm{~min}$ & $28 \mathrm{~min}$ & $1 \mathrm{~h} 33 \mathrm{~min}$ \\
7 & $3 \mathrm{~h} 30 \mathrm{~min}$ & $1 \mathrm{~h} 50 \mathrm{~min}$ & $35 \mathrm{~min}$ & $50 \mathrm{~min}$ \\
8 & $3 \mathrm{~h} 10 \mathrm{~min}$ & $2 \mathrm{~h} 44 \mathrm{~min}$ & $1 \mathrm{~h} 11 \mathrm{~min}$ & $55 \mathrm{~min}$ \\
9 & - & $1 \mathrm{~h} 40 \mathrm{~min}$ & $1 \mathrm{~h} 35 \mathrm{~min}$ & - \\
10 & - & - & $1 \mathrm{~h} 30 \mathrm{~min}$ & - \\
Média & $2 \mathrm{~h} 44 \mathrm{~min}$ & $2 \mathrm{~h} 17 \mathrm{~min}$ & $1 \mathrm{~h} 20 \mathrm{~min}$ & $1 \mathrm{~h} 04 \mathrm{~min}$ \\
\hline
\end{tabular}

TABELA 2: Tempo de dissoluçăo de polpa, nas diversas soluções.

\section{c. Estabilização}

Foram obtidos os seguintes resultados na tentativa de estabilizaçāo.

\begin{tabular}{|c|c|c|}
\hline $\begin{array}{r}\text { Solução } \\
\text { Titulação }\end{array}$ & $5,25 \%$ - Com NaCl & $5,25 \%$ - Sem NaCl \\
\hline $1:$ & $4,63 \%$ & $5,14 \%$ \\
\hline $2:$ & $4,26 \%$ & $4,26 \%$ \\
\hline 3 a & $4,05 \%$ & $3,80 \%$ \\
\hline $4 !$ & $3,62 \%$ & $3,18 \%$ \\
\hline $5:$ & $3,02 \%$ & $2,82 \%$ \\
\hline $6:$ & $2,78 \%$ & $1,92 \%$ \\
\hline 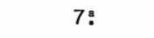 & $2,70 \%$ & $1,38 \%$ \\
\hline 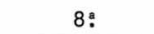 & $2,58 \%$ & - \\
\hline
\end{tabular}

TABELA 3: Perda de cloro ativo na solução de Hipoclorito de Sódio com e sem $\mathrm{NaCl}$ (Intervalo entre as titulaçōes: 2 meses).

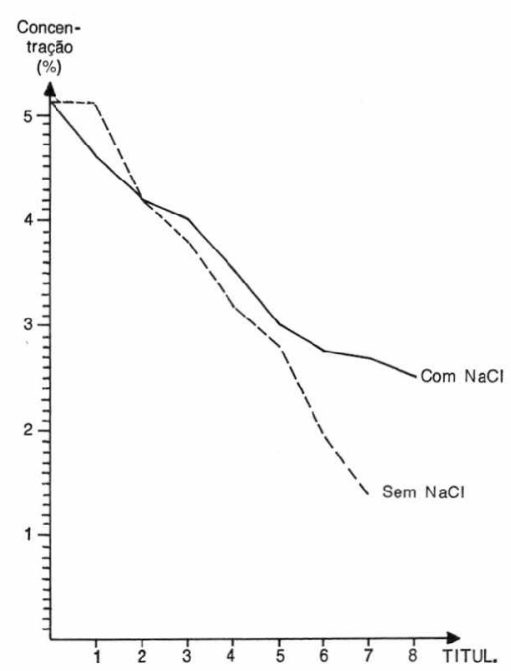

GRAFICO 2: Comportamento da perda de cloro ativo em soluçōes com e sem $\mathrm{NaCl}$.

\section{DISCUSSÃO}

\section{a. Envelhecimento dos $\mathrm{NaOCl}$}

1. Nảo existe aumento de concentração das soluçōes; é apenas artefato.

2. As sucessivas titulaçōes da Soluçāo Miltom demonstram que ela realmente é estável, dentro do prazo de validade (2 anos). Após o vencimento observa-se queda considerável na concentraçāo.

3. Quanto maior a concentração inicial $\operatorname{dos} \mathrm{NaOCl}$, mais rápida a perda, ou maior a perda mensal. Este fato foi observado também em trabalho semelhante.

4. Soluçőes frescas sāo praticamente estáveis, como o líquido de Dakin.

5. Observa-se maior queda na concentração nos meses de verão, devido ao calor.

6. No presente trabalho o líquido de $\mathrm{Da}$ kin já iniciou com $0,21 \%$, o que significa que ficou muito tempo estocado na farmácia.

\section{b. Tempo de dissolução da polpa}

Encontramos variaçōes nos tempos de dissoluçāo em uma mesma concentraçāo, provavelmente relacionados com certos fatores como:

- Quantidade de líquido usado

- Tamanho da polpa

- Agitação ou nảo do recipiente

- Constituição da polpa (mais ou menos fibrosa)

- Temperatura ambiente

\section{c. Estabilização}

1. $\mathrm{O} \mathrm{NaCl}$ nảo se mostrou eficaz como estabilizante.

É importante observar-se que, com a adição de $\mathrm{NaCl}$ à solução, houve maior queda inicial na concentração de cloro ativo. No entanto, a perda de cloro na solução com $\mathrm{NaCl}$ a $16,5 \%$ é menor do que na solução sem o $\mathrm{NaCl}$, no mesmo período de tempo.

2. Feito o doseamento do cloro ativo na soluçăo obtida, encontrou-se um teor de $0,35 \%$. Ao se verificar o $\mathrm{pH}$ das soluçōes uma semana após, notou-se que não houvera estabilização e que o mesmo estava muito diferente de 10. Assim năo houve possibilidade de tamponamento dessa maneira. No entanto, tudo indica que o aumento do $\mathrm{pH}$ da soluçāo é o caminho mais certo a seguir na procura da estabilizaçāo.

\section{CONCLUSÕES}

1. Há um "envelhecimento" (diminuiçāo da concentraçäo de cloro), dos Hipocloritos de sódio com o passar do tempo.

2. Quanto maior a concentração de cloro da solução, mais rapidamente dá-se a perda de cloro e, reciprocamente, quanto menor a concentração, menor é a perda de cloro.

3. As soluçōes com concentraçāo em torno de $2,5 \%$ de cloro mostraram-se as mais estáveis naturalmente.

4. A solução Miltom ( $1 \%$ de cloro) é realmente estável dentro do prazo de validade (mais ou menos 2 anos).

5. As soluçōes de $\mathrm{NaOCl}$ têm capacidade de dissolução de polpa dental, na razão direta de suas concentraçōes.

6. $\mathrm{O} \mathrm{NaCl}$ năo se mostrou eficaz como estabilizante.

7. Tudo indica que o aumento do $\mathrm{pH}$ da soluçāo seja o caminho certo para a estabilização.

8. Do que se expôs, é lícito considerarse a possibilidade de uso endodôntico de produtos (alguns) tipos "água sanitária" das marcas $Q$ Boa e Virex, que são soluçōes de $\mathrm{NaOCl}$ a concentraçōes de $2 \%$ e $1 \%$ respectivamente.

\section{REFERÊNCIAS BIBLIOGRÁFICAS}

1. AMERICAN DENTAL ASSOCIATION. Remédios dentários oficiais. 27. ed. Rio de Janeiro: USAID, 1963. p. 121: Antissépticos e germicidas de uso tópico.

2. BAZERQUE, P. Farmacologia odontológica. Buenos Aires: Mundi, 1976. p. 535-536.

3. BERBERT, A.; BRAMANTE, C.; BERNARDINELI, N. Endodontia prática. São Paulo: Sarvier, p. 53-59-62.

4. BEVILACQUA, S. Elementos de farmacologia e terapêutica. Rio de Janeiro: Científica, 1964. p. $159-160$

5. BUCKLEY, J.P. Matéria médica, farmacologia e terapêutica dentárias. 3. ed. Rio de Janeiro: Científica, 1956. p. 75-6.

6. CAUDURO, H. Manual prático de endodontia. 2. ed. Porto Alegre: Ed. R.G.D., 1969. p. 89-90.

7. COOLIDGE, E.D. Endodontia. Philadelphia: Lea \& Febiger, 1950. p. 157-158.

8. DE DEUS, Q.D. Endodontia. Belo Horizonte: Odontomédica \& Jurídica, 1973. p. 407. 
9. EUROPAISCHES ARZNEIBUCH, Komentar. Stutgart: Wissenschaftliche, 1976. p. 871.

10. FILGUEIRAS, J.; MELLO, C.F. Patologia da polpa dentária. 3. ed. Rio de Janeiro: Científica, 1955. p. 84-85.

11. GROSSMAN, L.I. Endodontia prática. 3. ed. Rio de Janeiro: Atheneu, 1963. p. 250.

12. GROSSMAN, L.I. Tratamento de canais radiculares. 2. ed. Rio de Janeiro: Atheneu, 1956. p. 236-237.

13. HIZATUGU, R. \& VALDRIGHI, L. Endodontia. Piracicaba: Aloisi, 1974. p. 150-151.

14. HOLLAND, R. Endodontia: Araçatuba: Faculdade de Odontologia, 1972. p. 44-45.

15. INGLE, J.I.; BEVERIDGE, E.E. Endodontia. 2. ed. Rio de Janeiro: Interamericana, 1979, p. 170.

16. LASALA, A. Endodoncia. 2. ed. Carácas: Cromotip, 1971. p. 199.

17. LIBEAU, P. \& JANOT, M.M. Traité de pharmacie chimique. 4. ed. Paris: Masson, 1956. v. 1. p. 32-39.

18. LEONARDO, M.; LEAL, J.M.; SIMŌES A.P. Endodontia: Sāo Paulo: Panamericana, 1982. p. 189-193.

19. MAISTO, O. Endodoncia. Buenos Aires: Mundi, 1967. p. 164.

20. NEIDLE, E.A.; KROEGER, D.C.; YAGELA, J.A. Farmacologia e terapêutica para dentistas. Rio de Janeiro: Guanabara Koogan, 1983. p. 577.

21. PAIVA, J.G.; ALVARES, S. Endodontia. 2. ed. Sảo Paulo. Atheneu, 1979. p. 165-166.

22. PAIVA, J.G.; ANTONIAZZI, J.H. Endodontia. Sảo Paulo, Artes Médicas, 1984. p. 308-309.

23. PUCCI, F.M. Conductos Radiculares. Montevideo: Medico-Quirurgica, 1944. v. 2, p. 364.

24. REDISH, G.F. Antisseptics, desinfectants, fungicids and chemical and physical sterilization. 2. ed. Filadélfia: Lea \& Febiger, 1961. p. 562-568.

25. ROGERS, G.H. A text book of inorganics pharmaceutical chemistry. Philadelphia: Lea \& Febiger, 1945. p. 199-201.

26. SALLES CUNHA, G. Terapêutica. 2. өd. Rio de Janeiro: Scientífica, 1945. p. 45-46.

27. SELTZER, S. Endodontology. Estados Unidos: Mc Graw Hill, 1971. p. 248-249.

28. SOLER; SHOCRON, Endodoncia. Argentina: La Médica, 1957. p. 217-218.

29. THE UNITED STATES PHARMACOPEA. Easton Mack, 1985. p. 1420. 